\title{
Resistance to Investigation of Crimes, Related to Human Trafficking: The Forms, Methods and Ways to Overcoming
}

\author{
Bakhyt Moldatjaevich, Nurgaliyev \\ "Bolashak" Karaganda University, Kazakhstan, 100012, Karaganda, Erubaev Street, 16 \\ Email:nbake@mail.ru \\ Alexey Vladimirovich, Boretsky \\ Innovative University of Eurasia, Kazakhstan, 140000, Pavlodar, M. Gorky Street, 102/4 \\ Email: alexey1977.77@mail.ru
}

Doi:10.5901/mjss.2015.v6n3s1p86

Abstract

The purpose of this article is to study the resistance to investigation of crimes, related to trafficking in human beings. The authors give an analysis of the concept, the forms and methods of the resistance to investigation of crimes, related to trafficking in persons in the Republic of Kazakhstan. In the study, based on the analysis of criminal cases, and the survey of law enforcement agencies' officers, engaged in combating human trafficking in Kazakhstan, the authors isolated and grouped the basic forms and methods of obstruction of investigation. Also, the study suggests possible ways to overcome the resistance to investigation of these crimes, and their use in the investigation of cases of trafficking in human beings, in order to increase the effectiveness of the investigation.

Keywords: trafficking, investigation of crimes, organized crime, obstruction of investigation of crimes, forms of obstruction of investigation.

\section{Introduction}

Currently, an increase of the organized crime is observed in the Republic of Kazakhstan, which is formed by various criminal groups, aimed at committing crimes related to human trafficking. In this connection, the issues of improving the efficiency of the fight against human trafficking are particularly relevant.

The practice of detection and investigation of crimes specified in the Art. 128 of the Criminal Code RK (Human trafficking), indicates that since the criminalization of trafficking 203 crimes were registered in the country (including in $2000-1,2001-4,2002-0,2003-1,2004-2,2005-7,2006-20$, in $2007-14$, in 2008 - 15, in 2009 - 21, in 2010 -22 , in $2011-25$, in $2012-21$, in $2013-33$, in $2014-17$ ), about $50 \%$ of the criminal proceedings were terminated for various reasons (Information on the registered crimes under Art. 128 of the Criminal Code RK on the territory of the Republic of Kazakhstan, 2015).

Successful detection and investigation of trafficking in human beings largely depends on how promptly, fully and accurately were identified and recorded its tracks, material objects and circumstances generated by a criminal act; it also depends on the analysis of information about the persons who committed the act or are potentially capable of it. Qualified clarification of the entities and details of the criminal event, based on a comprehensive study of the situation in which it occurred, makes establishing and exposing the culprit much easier.

The analysis of the investigative practice shows that the investigation of human trafficking in the Republic of Kazakhstan depends on a number of serious challenges, which include:

- $\quad$ an un developed legal framework;

- the lack of interagency cooperation at the national and international levels;

- an inadequate funding of law enforcement agencies engaged in combating human trafficking;

- the lack of proposals to improve the efforts to combat these crimes.

A survey of 150 investigators and operatives of RIA indicated that over $95 \%$ of them noted the need to develop valid scientific advice in the investigation of human trafficking.

The issues of the fight against trafficking in human beings have been already researched and a number of 
scientific works is dedicated to it, among which is necessary to note F. Laczko (2005), Seo-Young Cho et al. (2014), E. M. Gozdziak and E. A. Collett (2005), S. A. Limoncelli (2009), L. I. Shelley (2010), S. W. Stoecker (2010), D. M. Hughes (2014) and others authors.

The respondents surveyed by the authors, indicated that one of the circumstances, having a negative impact on the progress and quality of the investigation of human trafficking is counteractions of the persons concerned.

The problem of resistance to investigation of human trafficking is one of the insufficiently studied, despite the fact that some questions of the investigation of crimes related to trafficking in human beings have been previously studied in some works of such authors as: A. Farrell (2012), B. F. Kingshott (2014), J. M. Wilson and E. Dalton (2008), A. V. Boretsky and S. K. Zhetpisov (2013), S. Yu. Zhuravlev and A. M. Pigayev (2006), but the problems of obstruction of investigation of human trafficking in these studies are either not considered at all or not discussed enough. This, in turn, highlights the need for research of these issues.

\section{Research Methods}

In the methodological basis of the study lies the system of common, separate and special methodological principles, approaches and methods of scientific cognition, applicable either separately or in combination with each other. In particular, there have been used such methods as dialectical, historical, comparative analysis, simulation, statistical and systematic-structural, action and situational approaches to the study of the processes and phenomena.

In addition, the study used sociological techniques such as questionnaires and interviews with the victims, law enforcement officials and representatives of the crisis centers.

In the course of the present study, there was made an analysis of the criminal cases of human trafficking, considered in the courts and being under criminal proceedings, with the purpose of exposure of the investigation deficiencies and errors, committed by the investigation subjects.

In order to achieve the objective results of the study these methods were applied comprehensively.

\section{The Concept of Resistance to Investigation of Human Trafficking}

The practice of criminal proceedings on human trafficking indicates that the persons, counteracting the investigation, illegally influence both the traces of the crime, and the parties of the proceedings, because the purpose of the investigation resistance is preventing establishment of the truth in a criminal case of human trafficking and obstruction of prosecution of the "traffickers" themselves.

In this regard, illicit impact is mostly exerted on the sources and carriers of materially fixed and verbal information, that is, on the parties to the proceedings (witnesses, victims, defendants, suspects, experts, attesting witnesses, investigators, operational staff, judges, prosecutors, lawyers); as well as other persons, who are not involved in the process of the investigation (journalists, covering the investigation, corrupt government employees, etc.).

Typically the illegal influence is exerted not so much on the traces of the crime, as on the organizational and legal relations in the process of investigation. The immediate objects of such impact are the subjects of the criminal process, beginning with victims, witnesses and ending with investigators, judges (Bobrowski K. V., 1997).

Under the resistance to investigation of human trafficking should be understood a set of agreed actions (inaction) of persons, interested in preventing the establishment of objective truth in the criminal case of human trafficking for the purpose of evading responsibility of the perpetrators of this crime or to mitigate the punishment for trafficking in persons.

\section{Characteristic Forms of Resistance to Investigation}

The present research showed that organization and transnationality are the distinguishing features of resistance to investigation of human trafficking. This influences both the subjects of resistance against the investigation, and the ways of its implementation. The wrongful acts or omission occurring in the process may be related both to concealment of human trafficking as a whole and its certain elements, established during the investigation.

The analysis of the studied criminal cases provided in Art. 128 of the Criminal Code RK (Human trafficking) shows that regarding the resistance to investigation as a whole the following actions are taken:

- to conceal the fact of human trafficking as a whole (delay in procedural deadlines; unjustified termination of criminal proceedings, etc.);

- to conceal certain elements of trafficking (concealment or falsification of individual items and documents; obstructing the establishment of the motives, the identity of the offender, the place and time of the offense, the 
detection of the instruments of crime, the causes and conditions that contribute to its commission, etc.).

It should be noted that the abovementioned actions (or omissions) can be carried out both separately and in various combinations, different forms and methods.

When separating the forms of obstruction, the peculiarities of the information (physical and verbal) should be takes as the basis.

The impact on the sources and carriers of the material information (i.e. on the traces) is characterized by the implementation of actions such as destruction, falsification, concealment, etc., and on verbal sources and carriers bribery, blackmail, slander, threats, including killing.

In turn, the impact on verbal sources and carriers of information can be both psychological and physical. Moreover, in both cases there is carried out both a direct and indirect impact.

The obstruction can be carried out in the active and passive forms. The passive forms, inactive in nature, include: failure to render assistance, failure to perform a required act, failure to give the requested information, failure to deliver the required items, failure to appear when summoned, non-disclosure of the known facts, refusal to testify, etc.

To the active forms of obstruction relate: perjury, concealment and destruction of objects required in the proceedings, pretense, alibi, incitement to disobedience, direct resistance to the investigator, bribery, blackmail, physical elimination of witnesses, etc.

Among them, Z. I. Kirsanov includes: escape from the crime scene and concealment from the investigation and trial bodies, the inducement to false testimony, forgery of documents false documents (Kirsanov Z. I., 1997).

The forms of resistance to investigation can be also classified on other grounds. For instance, due to the degree of activity of the resistance subjects and intensity of emotionsthere distinguish the acute and low-intensity resistance; the frequency of occurrence - thetypical and specific; the duration of existence - short-term and lasting.

\section{The Typical Ways of Resistance to Investigation}

The considered forms of resistance to investigation of human trafficking are fulfilled in certain ways. The categorization according to the abovementioned types of information (verbal or material) and its carriers would be the most effective.

The methods of influence on the sources and carriers of the verbal information, i.e. humans, in turn, can be divided into two groups:

1) Methods of mental influence (bribery, slander, blackmail, threats of violence, persuasion to induce compassion for the suspect, etc.);

2) Methods of physical impact (violence against a person, possessing specific information or against his relatives, their torture, hostage-taking, destruction of property, murder, etc.).

The methods of influence on the sources and carriers of the verbal information, as can be seen from their content, basically are independent legally defined crimes, provided in the criminal legislation of the Republic of Kazakhstan. Thereafter, modus operandi of such crimes, to some extent, characterizes the ways of resistance to investigation of past crimes. Such circumstances are most typical for counteraction within the scope of organized criminal activity. Such methods of obstruction inevitably involve generation of new material and ideal traces of crimes that are legitimate to be considered in terms of additional features, not only in the detection and investigation of crimes, including committed in order to hinder the investigation of human trafficking, but also in the analysis of crime of human trafficking as a whole.

The methods of influence on the sources and carriers of material information, "on the material traces of crime", to certain extent, are related to the methods of concealment of crimes. These are concealment of information, its disguise, falsification, destruction, etc. However, unlike the concealment of crimes, in order to resist the investigation, such methods are used by a much broader range of people, including corrupt officials, representatives of governing bodies, bodies of preliminary investigation, prosecution, courts. Certainly, they have more significant possibilities to implement such methods, including the use of third parties for the implementation.

It must be said, that in the general system of resistance to investigation the target of impact (mental or physical) is always a person (the subject of the investigation, the victim of trafficking, a witness) as the source and carrier of forensically relevant information. And then a person, affected by particular impact, provides available actions for distortion or destruction, falsification or disguise of relevant information. In this situation, the person becomes not only the recipient of influence, but also the subject of resistance. The mode of action of the person depends on his position in criminal proceedings and in the structures of power, the relation to the crime under investigation and the bodies conducting the investigation. For example, the corrupt representatives of governing bodies, officials of the organizations and institutions often affect the process of investigation of human trafficking as a whole in the form of requests or instructions to the persons, engaged in the investigation of human trafficking. A similar situation emerges in the relations of the leader of a 
criminal group or community of traffickers and the corrupt investigator.

This category of the subjects of resistance to investigation is indifferent to whom and what will be falsified, destroyed, fakes, because only the result is important to them.

In this regard, there can be distinguished three main groups of the countermeasures subjects:

- the subjects of the criminal proceedings (victims of trafficking, witnesses, suspects, etc.);

- the subjects of a criminal investigation (corrupt investigators, employees of the inquiry, the prosecutor's office, etc.);

- the persons, not directly related to the investigation (corrupt representatives of the governmental bodies, leaders and members of criminal organizations).

Considering that, the mode of action can be specified:

1) The impact on the sources and carriers of the verbal information:

- Psychological (persuasion, bribery, threats, blackmail, compromise, provocation, destruction of property);

- Physical (murder, assault, torture, illegal detention, kidnapping).

2) The impact on the sources and carriers of the material information (on the traces of crimes) destruction; pretense; falsification; concealment (disguise); distortion.

3) The impact on the investigation process as a whole: illegal orders of bodies, supervising the inquiry and investigation; falsification of procedural documents; loss (destruction) of procedural documents; adoption of "satisfactory" decisions; delaying the timing of decisions; non-performance of the decisions.

Note that since a person is both the object of the impact and the subject of resistance, then the modes of action for this purpose are universal, the same subjects can influence the sources and carriers of both the verbal and material information.

The only exception are, perhaps, the means of influence on the process of crimes investigation of the subjects in authority, in general, in relation to the other participants in the reaction. As a rule, they do not persuade, blackmail, destroy anything and falsify themselves. This "dirty work" is performed by their "messengers", including cases when it is associated with impact on the sources of verbal information.

Thus, the influence on such sources is the key that determines the importance in the common system of counteraction. Eventually, it all depends on the person, especially possessing or disposing of the relevant information.

The analysis of the survey results of the investigators involved in the investigation of trafficking cases and criminal proceedings of trafficking allow identifying the most common ways of influencing the non-verbal carriers and sources of information on cases of human trafficking:

1) Concealing information. Under concealing information is understood keeping the investigator in ignorance about these or other circumstances of the case under investigation or sources required to establish the truth of information. Concealing can be performed in both the active and passive forms.

To the methods for withholding information in relation to trafficking, include: throwing, destruction, concealment of a wide variety of evidence of the offense; failure to report about known preparing or committed crimes; failure to report the requested information, relevant to the case, to the investigate authority; failure to appear, or failure to appear when summoned to the body conducting the criminal proceedings; refusal to testify and omission of the known and interesting to the investigator information and (or) its carrier; failure to comply with the requirements of the officials of the investigator; non-delivery (voluntary) of the desired instruments of crime.

The results of this analysis demonstrate that despite the different frequency of these ways, the effectiveness of counteraction largely depends on their combination.

2) Concealment of items, is the most frequently used method of resisting the investigation. The results of this analysis demonstrate that despite the different frequency of these ways, the effectiveness of counteraction largely depends on their combination.

3) Destruction of information about the crime and (or) its carriers refers to complete or partial destruction of the fixed reflections of the crime, the signs its perpetrators and the carriers of these reflections. Destruction can be complete or partial. Partial destruction borders to falsification and sometimes is intertwined with it. Our study showed that, as a rule, destruction of documents is the method for data destruction in the commission of human trafficking, as well as carriers of such.

4) Disguise is changing the idea about the method of committing the crime, the personality of the perpetrator, the purpose of the objects-carriers of information and their circle. The study revealed the following methods of disguise: changing the appearance of the perpetrators of the crime; changing the appearance of the victims of the crime. 
5) Falsification is creation of false information about the crime and its perpetrators, as well as carriers of such information. To the methods of falsification of information include: creation of a false alibi; complete forgery; partial forgery. Falsification occupies a significant place in the system of counteractions to investigation of human trafficking.

6) Frame-up refers to mixed methods of concealment of crimes. It is defined as creating an environment that does not correspond to the actual event that has had occurred at this scene, this environment can be supplemented with consistent behavior and false reports of the frame's performers, and persons associated with them (Belkin R. S., 1979).

Frame-up is classified in special literature according to the following reasons:

- the purpose (concealment of the crime, concealment of non-criminal events);

- the object (framing of crimes, non-criminal events, separate details of the offense or separate elements of composition, frame of a frame-up);

- the time (implemented prior to the offense, at the time of the crime, after the crime);

- the subject (committed by a criminal (criminals), other persons);

- the place (at the crime scene, in a different place);

- the method of legalization (intended for detection upon reports of the perpetrator or related persons; designed for detection of unrelated persons);

- the duration of impact (designed to totally conceal the true event, intended to gain time or other temporary advantages over investigator);

- the content (to fake material traces of events, to fake material traces of events in conjunction with the appropriate behavior and delivering false information) (Belkin R. S., 1979).

As a rule, all these methods of frame-up are associated with a material environment.

Furthermore, let's consider the common methods of influencing the carriers and sources of verbal information in the practice of investigation of human trafficking cases.

1) Bribery is incitement of the investigator, the victim, a witness or any other person for the joint execution of investigation counteraction by the perpetrators with the help of money, gifts, services, benefits or promises. Bribery is a rare method of obstruction of the preliminary investigation in cases of trafficking in human beings.

2) Threats and persuasion are very similar, often complementary methods, aimed at persuading a person to commit certain actions (in order to obstruct the investigation) for reasons of humanity, compassion for another person or in order to guarantee their own safety and well-being of families. These techniques are implemented by means of communication: in person, by telephone, in writing. At the same time, under the threat is understood the promise to cause the person or his relatives material or physical harm in case of noncommitting the satisfactory actions. For instance, the DIA of Sharbakty district in the Pavlodar region, under Art. 128 of the Criminal Code RK, started criminal proceedings against individuals E. and T., who had illegally used the labor of an individual Z. in logging in May 2009 and caused harm to the health of the latter. Subsequently, the relatives of the accused had influenced the victim by means persuasion, who then has changed his testimony which in turn led to termination of the criminal prosecution under Art. 128 of the Criminal Code RK and further requalification of the actions of the accused under Art. 104 of the Criminal Code $\mathrm{RK}$, and, finally, to the termination of the criminal case for lack of evidence of a crime (Criminal case No 09550003100098, 2010).

3) Blackmail is a promise of the subject of obstruction to disclose (spread) compromising or revealing information about the person or his relatives in the event of non-compliance. In this regard both untrue and slanderous intelligence may be used. Persuasion is characterized by impact on feelings of people from the point of compassion for the suspect and his relatives.

In the event that persuasion, threats and blackmail do not have the desired effect, there are used the methods entailing the property damage, physical suffering, anxiety for the fate of relatives (kidnapped, illegally deprived of freedom). These techniques of influencing are used without prior warning of their possibility by the subjects of obstruction for the accomplishing of their threats.

4) Provocation is incitement of the person of the perpetrators' interest to perform such actions that entail adverse effects for the person.

Usually, provocation occurs in three varieties:

- provocative actions, aimed at discrediting of the investigator and used without preliminary incentive of the latter to active crime investigation (proposal to accept a gift as a sign of respect or to start intimate relations 
with a woman, sometimes false, etc.). Such facts are recorded using covert photography or video and then used for threats and blackmail;

- the actions, encouraging to active performance of duties during the investigation, in the course of which the investigator is being discredited. For instance, initially, a telephone message of the witness to the case states of impossibility to arrive for questioning and suggests to accomplish it at his place of residence, after that, upon arrival of the investigator, the actions to discredit the investigator are carried out;

- the actions, impelling the investigator to conduct inefficient active measures in the crime investigation. For example, an anonymous message of the fact of human trafficking, that rouses the investigative bodies to send a SOG, which does not find the desired; or an anonymous message about concealing evidence by the suspect, on the basis of which a long unsuccessful search of the corresponding object is carried out (Zhuravlev S. Yu., 1992).

5) Slander is both a lie, discrediting someone and propagation of untrue insinuations against the persons, who do not wish to accomplish or do not accomplish certain required actions. It can be both oral and written, in the form of publications, media reports or messages to the prosecutor, supervising the investigation, about the alleged illegal actions of the investigator. For example, during the investigation of the criminal case, filed under Art. 128 of the Criminal Code RK, against individuals I. and K., who had illegally used labor of individuals D., K., M. and T. in the autumn of 2006, in the suburbs of Semey city, the defendants made an attempt to defame the investigator and operatives, through filing a complaint to the prosecutor, stating that in the course of detention the investigator and operatives have had assaulted and humiliated individuals I. and K. At the time of verification of this fact, both by the prosecutor's office and, subsequently, by the court, this information was not confirmed (Criminal case No 07632803101382,2007 ).

6) Consulting is providing advisory assistance by experienced subjects for the persons, interested and having the opportunity to exercise obstruction of an ongoing investigation. The advice can apply to the line of behavior, during the investigative actions, simulation, concealment, falsification of evidence, etc. The persons, already convicted, lawyers and colleagues may serve as consultants. The suspects ask for advice the most often, the least - their relatives and friends.

It should be noted that, in addition to the previously mentioned methods of psychological impact on the sources and carriers of forensically relevant information (that is people), there are the ways of physical influence. It is exerted on both the investigators and other participants of the investigation (the victims, experts, interpreters, and others.).

The possibility of implementing the methods of influence on the whole investigation process is possessed by the corrupt representatives of government bodies, relevant law enforcement officials and the connected leaders of organized criminal groups or communities. Identification of such connections is extremely difficult, because they often occur at the level of individuals, more resourceful (powerful) than the investigator.

\section{The Measures to Overcome the Resistance to Investigation}

Upon research of the basic forms and methods of resistance to investigation of human trafficking, it is advisable to proceed to analysis of the measures to overcome the resistance to investigation of human trafficking.

Thus, T. B. Averjanova and R. S. Belkin divide the means and methods of overcoming the resistance to investigation of crimes into two groups:

- the means and methods to overcome the attempts to conceal the crimes;

- the means and methods of overcoming other forms of obstruction of investigation.

To the first refer the investigative and search actions, appeals to the help of population and the media, to the second - the operational-search activities, departmental investigations, the official talks, the speeches of the inspector and other officials in the work collectives, the media, etc. and, in exceptional cases, introduction of the subjects of resistance with separate circumstances and materials of the case, on condition of maintaining a proper degree of investigative secrecy (Averjanova T. V. and Belkin R. S., 1997).

The most comprehensive system of measures to neutralization of the obstruction of investigation has had outlined A. A. Petrova, referring to them are the following:

- selecting the right line of behavior when dealing with criminals; application of tactics, especially designed for situations of resistance to investigation;

- the application of operational search information about the intentions of the criminals for the obstruction of the investigation; 
- the use of the effect of surprise when dealing with criminals and the forensic techniques designed in this regard, including the methods of reflexive control;

- the utilization of operative search units for protection of the witnesses and victims from the unlawful influence of the interested persons;

- encryption of information about the witnesses and victims in the procedural documents;

- the use of special technical means (audio, video and other equipment), excluding direct contact of the witnesses and victims with the suspects and accused persons, during separate investigative actions (confrontation, submission for identification);

- identification and neutralization of individuals contributing to information leakage, and those persons, who try to exert pressure on the investigation; disorientation of the criminal about the intents of investigation;

- conducting an internal investigation or operational departmental inquiry in respect of persons, suspected of connections with criminals;

- discharge of the investigators and operatives, proved of cooperation with criminals, from the investigation and submitting the case to investigators from another unit;

- tactically clever course of action, when dealing with the defenders of the accused, during the investigation;

- the use of computer technology;

- the use of "incentive" norms of the Criminal Code in respect of the individual participants of the criminal process;

- in exceptional cases, acquaintance of the opposing parties with the separate circumstances and materials of the case, for resolving the current conflict;

- timely publication of the elaborate information on the progress and results of the investigation in the press (Petrova A. N., 2000).

The foregoing indicates a varied approach of the researchers to the definition of the means and methods of neutralization of resistance to investigation of crimes, the complexity and comprehensiveness of this activity.

In our opinion, it is wrong to refer this activity to a derivative of the investigation process. This is one of the areas of crime investigation and the achievement of its objectives is provided by the same means and methods, as in the search for objects, detention of the causes and conditions that facilitate the commission of crimes, etc.; that is, the investigative activities, organizational and operational-search activities. Therefore, the means of overcoming the resistance to investigation are investigative actions, organizational and operational-search activities. In the process of their implementation, technical, forensic and tactical activities are utilized.

In consideration of the foregoing, the measures to overcome the resistance to investigation of the facts of human trafficking can be organized as follows:

- determination of the correct course of action of the investigator in contact with the accused and the defender;

- application of security precautions to the victims of trafficking and the witnesses, stipulated by the criminal procedural law;

- application of operational-search information and tactics;

- detection and neutralization of officials, directly or indirectly interested in the outcome of the case;

- utilization of the media in coverage of the investigation of the facts of human trafficking.

\section{Conclusions}

Obstruction of the investigation of human trafficking is one of the circumstances that complicate, and sometimes have a negative key impact on the quality of investigation of the criminal proceedings on human trafficking.

The subjects of resistance to the investigation of human trafficking are:

- the subjects of criminal proceedings;

- the subjects of the crime investigation;

- the persons not directly related to the process of investigation.

The main forms of resistance to investigation of the cases of trafficking in human beings are distinguished into:

- influence on the sources and carriers of the verbal information, which is subdivided into psychological (persuasion, bribery, threats, blackmail, compromise, provocation, destruction of property) and physical (murder, assault and battery, torture, unlawful deprivation of freedom, kidnapping);

- influence on the sources and carriers of material information (destruction, frame-up, falsification, concealment 
(disguise), distortion);

- influence on the investigation process as a whole (illegal instructions of authorities, supervising the inquiry and investigation, falsification of the procedural documents, their loss (destruction), adoption of the "satisfactory" solutions, delaying the timing of decisions, non-performance of the decisions).

Among the measures, aimed at overcoming the resistance to investigation of human trafficking should be highlighted as follows:

- determination of the correct course of action of the investigator in contact with the accused and the defender;

- application of security precautions to the victims and witnesses, stipulated by the criminal procedural law;

- application of operational-search information and tactics;

- detection and neutralization of officials, directly or indirectly interested in the outcome of the case;

- utilization of the media in coverage of the investigation of the facts of human trafficking.

Thereby, the elucidation of the law enforcement officers the basic forms and methods of obstruction of the investigation of human trafficking, as well as adoption of necessary measures to overcome the resistance to investigation in these cases, can largely ensure the most efficient detection and investigation of crimes, related to human trafficking and bring the perpetrators to justice.

\section{References}

Averjanova, T. V., Belkin, R. S. (1997) Forensic support of the criminal police and the preliminary investigation units. Moscow. Novy Jurist.

Belkin, R. S. (1979) Soviet criminalistics course. Vol. 3. Moscow. Publishing House of the Academy of Ministry of Internal Affairs of the USSR.

Bobrowski, K. V. (1997) On the status of resistance to investigation and concealment of crimes. The organized resistance to detection and investigation of crimes and measures to neutralize it. Moscow. JI MIA Russia, 103-108.

Boretsky, A. V., Zhetpisov, S. K. (2013) Human Trafficking: Issues of Investigation Techniques. World Applied Sciences Journal, 23(1), 13-17.

Cho, Seo-Young, Dreher, A., Neumayer, E. (2014) Determinants of Anti-Trafficking Policies: Evidence from a New Index. The Scandinavian Journal of Economics, 116(2), 429-454.

Criminal case No 07632803101382 (2007) City court of Semey city. Archive.

Criminal case No 09550003100098 (2010) Department of the Committee on Legal Statistics and Special Records of the General Prosecutor of the Republic of Kazakhstan in Pavlodar region. Archive.

Farrell, A. (2012) Identifying challenges to improve the investigation and prosecution of state and local human trafficking cases (Doctoral dissertation). Urban Institute.

Gozdziak, E. M., Collet, E. A. (2005) Research on Human Trafficking in North America: A Review of Literature. International Migration, 43(1-2), 99-128.

Hughes, D. M. (2014) Trafficking in Human Beings in the European Union: Gender, Sexual Exploitation, and Digital Communication Technologies. SAGE Open, 4(4), DOI:10.1177/2158244014553585.

Information on the registered crimes under Art. 128 of the Criminal Code RK on the territory of the Republic of Kazakhstan for the period from 2000 to 2014 (2015) The Committee on Legal Statistics and Special Records of the General Prosecutor of the Republic of Kazakhstan. [Online] Available: http://service.pravstat.kz/portal/page/portal/POPageGroup/Services/Pravstat.

Kingshott, B. F. (2014) Investigation of Human Trafficking. Combating Human Trafficking: A Multidisciplinary Approach, 91-118.

Kirsanov, Z. I. (1997) The role of forensic methods and means in the fight against resistance to detection and solution of crimes. The organized resistance to detection and investigation of crimes and measures to neutralize it. Moscow. JI MIA Russia, 146-150.

Laczko, F. (2005) Data and Research on Human Trafficking. International Migration, 43(1-2), 5-16.

Limoncelli, S. A. (2009) Human Trafficking: Globalization, Exploitation, and Transnational Sociology. Sociology Compass, 3(1), $72-91$.

Petrova, A. N. (2000) Resistance to investigation, forensic and other measures to overcome it. (Dissertation of Candidate Juridical Sciences). Volgograd.

Shelley, L. I. (2010) Human Trafficking: A Global Perspective. Cambridge. University Press.

Stoecker, S.W. (2010) Human Traffic And Transnational Crime: Eurasian And American Perspectives. Oxford: Rowman \& Littlefield.

Wilson, J. M., and Dalton, E. (2008) Human Trafficking in the Heartland Variation in Law Enforcement Awareness and Response. Journal of Contemporary Criminal Justice, 24(3), 296-313.

Zhuravlev, S. Yu. (1992) Counteractions to the detection and investigation of crimes and tactics to overcome it (Dissertation of Candidate Juridical Sciences). Nizhny Novgorod.

Zhuravlev, S. Yu., Pigajev, A. M. (2006) Trafficking in humans: mechanism of criminal activity, the method of investigation. Moscow. Jurlitform. 